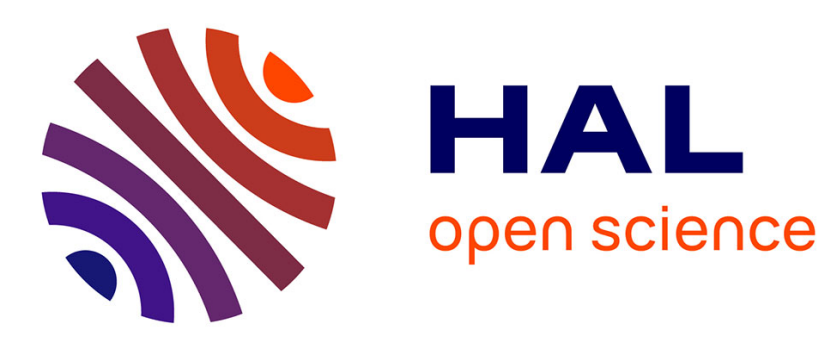

\title{
Phenomenon of Spiral Vortex Formation Over the Skock Wave Front
}

\author{
V. Sobolev, I. Hogset Hove
}

\section{To cite this version:}

V. Sobolev, I. Hogset Hove. Phenomenon of Spiral Vortex Formation Over the Skock Wave Front. Journal de Physique IV Proceedings, 1997, 07 (C3), pp.C3-127-C3-129. 10.1051/jp4:1997324 jpa00255481

\section{HAL Id: jpa-00255481 https://hal.science/jpa-00255481}

Submitted on 1 Jan 1997

HAL is a multi-disciplinary open access archive for the deposit and dissemination of scientific research documents, whether they are published or not. The documents may come from teaching and research institutions in France or abroad, or from public or private research centers.
L'archive ouverte pluridisciplinaire HAL, est destinée au dépôt et à la diffusion de documents scientifiques de niveau recherche, publiés ou non, émanant des établissements d'enseignement et de recherche français ou étrangers, des laboratoires publics ou privés. 


\title{
Phenomenon of Spiral Vortex Formation Over the Skock Wave Front
}

\author{
V. Sobolev and I. Hogset Hove*
}

State Mining, University of Ukraine, Prospekt K. Marksa 19, 320600 Dnepropetrovsk, Ukraine

* Forskingsveien I, Dept. of casting and Metal Forming, SINTEF, P.O. Box 124 Blindern, 0314 Oslo,

Norway

\begin{abstract}
Generation of spiral vortices was found to occur in explosive processing of graphite-copper mixed powders in cylindrical setups. The material in a vortex was distributed according to the atomic weights of its constituents, so that lighter constituents were concentrated in the center while heavier ones at the periphery. Indepth studies into this effect have suggested some materials engineering applications and a vortex model for the structure of the cloud that evolved into the solar system.
\end{abstract}

Résumé : La formation de tourbillons dans les matériaux est révélée au cours de la compaction par choc d'un mélange de poudres de cuivre et de graphite. Les tourbillons sont caractérisés par une distribution de matière correspondante aux masses atomiques des constituants ; les constituants plus légers sont situés près du centre, pendant que les constituants plus lourds sont situés à périphérie. Par analogie avec les tourbillons expérimentaux, certains traitements de matériaux et le nuage de matière lors de la formation du système solaire ont été modélisés.

A cord-like cavity close to sample center was found to form in dynamic processing of a porous material in a cylindrical setup [1]. It was realized that the cavity formation produced some negative effects from the engineering standpoint and also was a physical phenomenon of scientific interest. For these reasons, experiments aimed at finding the causes behind it were carried out in parallel to process engineering research needed to prevent cavity formation. It was found that compound decomposition and synthesis and polymerization reactions tend to be especially rapid in a region adjacent to the geometric axis of sample and that these processes are initiated by the leading shock wave front (LSWF) $[1,2]$.

The fundamental studies revealed an overall picture of the process [2] while the experimental results helped fulfill the engineering tasks. It was found that the flow of matter behind the curved leading shock front was of turbulent type featuring chaotic particle displacements at high gradients of mass flow rate.

The experimental studies into the flow of matter behind the LSWF elucidated a number of exciting physical effects that take place in powdered materials. For the first time, spiral-vortex-like structures were discovered in the sample central section subjected to stresses from the LSWF in explosive processing of copper-graphite mixed powders [3].

The structures of the starting material and the sample portion subjected to the LSWF differed not only in the outward appearance. While no phase transformations or structural changes occurred in the simple portions traversed by oblique (incident) shock wave as represented by $A C$ and $B D$ lines in Fig. la, melting due to higher temperatures and pressures was detected in the central portion confined within the cylindrical surface 7 (Fig. la), that is the tangential discontinuity surface. The motion of sample particles is a resultant of axial translational motion aligned with the charge detonation front travel (shown with an arrow in Fig. 1a) and rotational motion about the sample axis.

It was found that, as the curvature of LSWF is decreased, the flow of constituents gradually takes the form of segregation of particles of the lighter graphite near the axis of rotation instead of a spiral vortex, sec Fig. 2. Further motion of the flow occurs along a helix with a large lead. 
Following explanation may be suggested for the vortex generation. Let a parallel flow of particles with a unique velocity component run on a curved shock wave front, Fig. 3. By continuity of mass, momentum and energy, the velocity component normal to the front should become discontinuous and display a drop at the front while the tangential component remains constant. Therefore, the flow behind the shock wave front will no longer be parallel, and the motion will cease to be unidimensional. A transverse velocity component will thus appear while the longitudinal component will become dependent on the transverse coordinate. This means that the vorticity generally will diverge from zero, $\operatorname{rot} v \neq 0$.

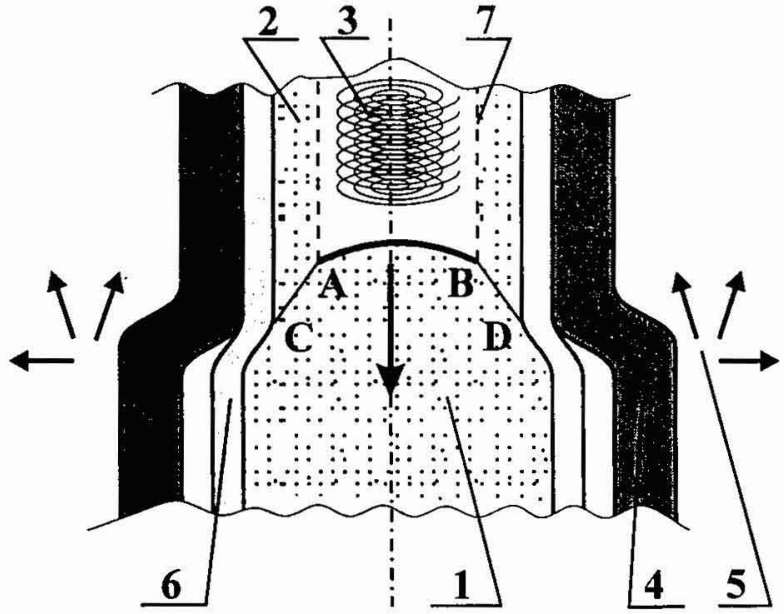

a)

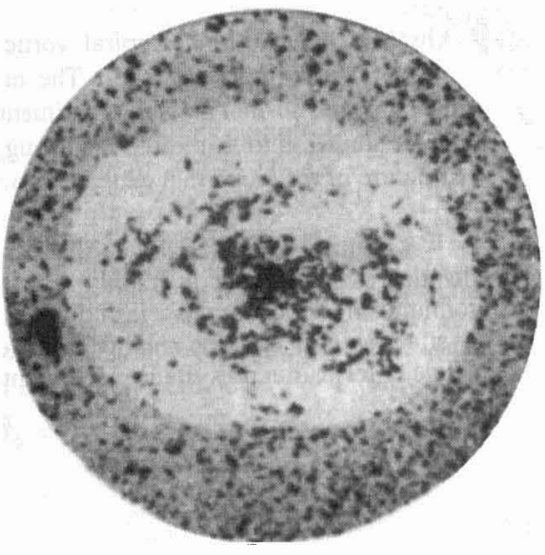

b)

Figure 1: Schematic of shock-wave-induced powder flow in a cylindrical device (a) and photomicrograph of section of explosive-compacted mixture, $100 \times$ (b). In the micrograph, the central light-colored area represents the region affected by the leading shock wave front denoted by $A B$ in (a). A vortex of graphite particles embedded in solidified copper can be seen in the area. The dark ring surrounding the light-colored area corresponds to the region affected by oblique shock wave front, $A C$ and $B D$ in (a). 1, powder mixture in initial condition; 2, sample region affected by oblique shock wave front $(A C, B D) ; 3$, central sample region affected by curved leading shock front $A B ; 4$, cylindrical tube; 5 , explosive detonation products; 6 , cylindrical tubular container; 7 , tangential discontinuity surface separating the sample regions affected by different pressures and temperatures.

That sample particles do rotate was indirectly validated by experiment [4]. A metal target was fixed against the bottom end of the setup instead of the bottom cover. The flow of particles therefore moved from the tubular container 6 uninhibited (see Fig. 1a), leaving a vortex-like trace pattern on the target. The spirals were generally clockwise. In its physical and chemical properties, the material thus applied to the target differed dramatically from both the target material and the sample constituents.

For example, the microhardness of layers 0.4 to $0.8 \mathrm{~mm}$ thick thus produced was more that 3.5 times that of the annealed copper precursor. In some areas, especially those adjoining the target, the microhardness was increased 4.5- to 5-fold. This type of processing performed at extremely high pressures and temperatures and possibly followed by quenching, shows promise for materials engineering. Furthermore, it was in the central sample part that the degree of transformation of graphite to diamond was at its maximum, the polycrystal size reaching $0.3 \mathrm{~mm}$.

One other noteworthy feature is what is termed dynamic separation effect [4]. X ray diffraction and electron microscopy revealed that the material behind the LSWF is separated not only at a macroscopic but also at an atomic level, so that lighter elements become concentrated in the vortex core while heavier ones at vortex periphery.

By analogy with the experimental vortices one can assume that the vortex that evolved into the solar system also had a distribution of components by mass. Furthermore, second-order spiral structures, that is 
protoplanetary matter vortices developing at spiral branches probably displayed similar behavior. It therefore appears that the Earth's evolution should be approached from the standpoint of a light core, which means a possibility of a radical change in our views on genesis of the Earth and other planets.
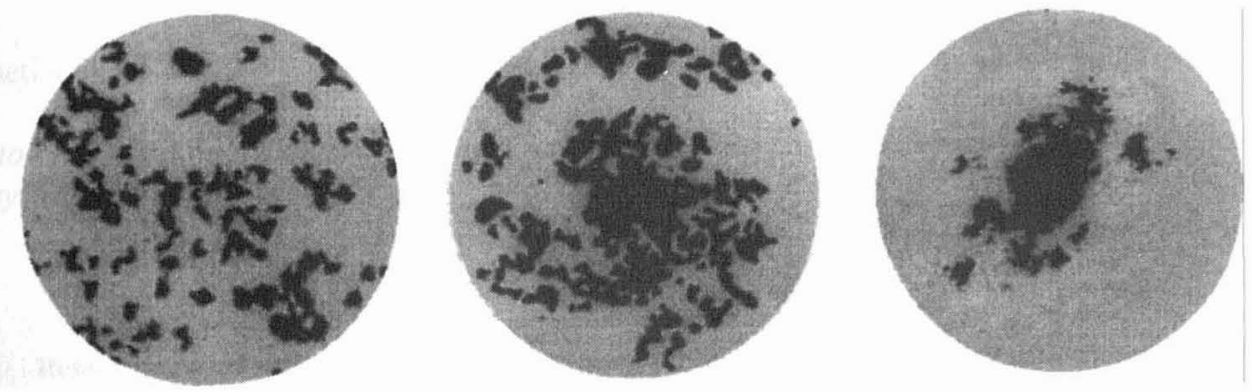

Figure 2: Photomicrographs of sample mixture sections following explosive processing. The distance from sample top is increasing from left to right. $100 \times$.

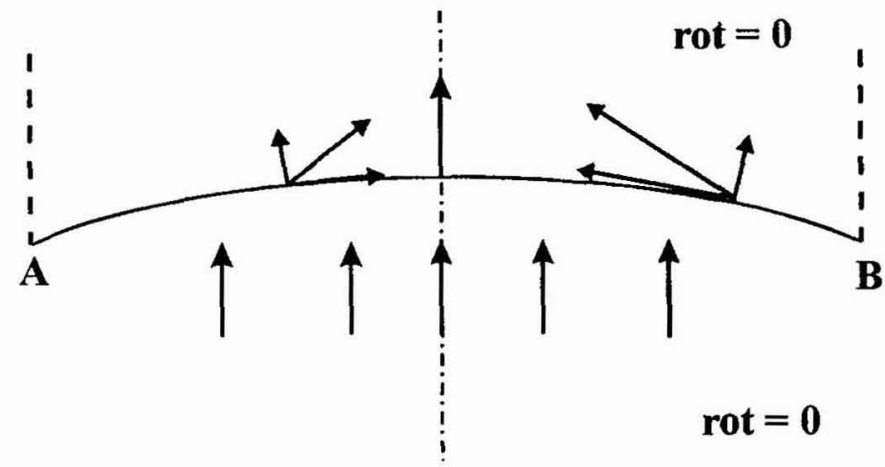

Figure 3: Vortex generation at curved shock front.

Based on the data of comprehensive experimentation, it can be concluded that a previously unknown phenomenon was experimentally discovered that consists in generation of spiral vortices in a porous medium behind a curved front of a shock wave due to a stepwise decrease in the normal component of the velocity vector of the medium constituents and to their distribution by mass such that lighter ones become concentrated at the vortex center while the heavier ones at its periphery.

The above phenomenon was utilized in designing pioneering pressurizing devices for e.g. synthesis of diamond, chaoite and other allotropic forms of carbon [5-7], and in developing materials with unique combinations of properties.

\section{References}

[1] Batsanov S.S., Doronin G.S. and Stupnikov V.P., Inzhenerno-fizicheskii zhurnal, 4 (1967) 672-674.

[2] Deribas A.A. and Staver A.M., Fizika goreniya i vzryva, 4 (1974) 568-578.

[3] Sobolev V.V., Pis'ma v zhurnal tekhnicheskoi fiziki, 10 (1984) 459-463.

[4] Sobolev V.V., Obogashchenie poleznykh iskopaemykh (Mineral dressing) (Tekhnika, Kiev, 1987) pp. 63-68.

[5] Sobolev V.V., Fizika i khimiya obrabotki materialov, 5 (1985) 140-142.

[6] Sobolev V.V., Fizika i tekhnika vysokikh davlenii, 3 (1992) 123-126.

[7] Sobolev V.V., Slobodskoi V.Y., Selukov S.N. and Udoyev A.A., Int. Geology Review, 28 (1986) 680-683. 